Gagnon, S. G., \& Nagle, R. J. (2004). Relationships between peer interactive play and social competence in at-risk preschool children. Psychology in the Schools, 41(2): 173-189 (Feb 2004). Published by Wiley-Blackwell (ISSN: 0033-3085). [The definitive version is available at www3.interscience.wiley.com]

\title{
Relationships Between Peer Interactive Play and Social Competence in At-Risk Preschool Children
}

\author{
Sandra Glover Gagnon and Richard J. Nagle
}

\begin{abstract}
Relationships between peer interactive play and social competence in a sample of preschool children $(N=85)$ considered at risk for academic difficulties were examined. Ratings of peer interactive play and social emotional development were collected from parents and teachers on the Penn Interactive Peer Play Scale and Vineland Social-Emotional Early Childhood Scale. Multivariate techniques revealed significant correlations between parent and teacher ratings on the measures. Results are discussed within the context of conducting multifaceted, ecological assessments of preschool children. Implications for school psychologists are noted with regard to the important associations between peer interactive play and social-emotional development. The psychometric integrity of the PIPPS is further validated and extended beyond the initial standardization sample to include a sample of primarily Caucasian children living in a more rural area.
\end{abstract}


Relationships between play and child development have been well established in theory and empirical studies. Play is a natural activity for young children (Lowenthal, 1997) and provides an important window through which to view development (Pellegrini, 1998). Play contributes to growth in cognitive, language, social-emotional, and academic skills. Since these domains tend to be emphasized in preschool curricula, they are readily observable and open to intervention. Children enjoy play and are motivated to engage in it, expending substantial social and cognitive energy in play activities. Because play proceeds through a regular developmental sequence during childhood, evaluations of children's play can provide indications of maturation and social competence (Fewell \& Kaminski, 1988). In recognition of this potential, play-based measures have been developed to assess intellectual, social-emotional, and communication skills in young children.

Although growth in the field of play assessment is evident, the extant literature supporting the psychometric properties of play measures is sparse. Thus, measures of play are rarely incorporated into assessment batteries. Perhaps this traditional lack of inclusion of play measures has been appropriate, given the lack of valid, standardized measures that have typically been available. In his meta-analysis, Fisher (1992) found that across the studies of play examined, minimal documentation and validity data were reported for the play measures used. In addition, measures were not described in detail, making replications quite difficult, if not impossible. However, based on the existing knowledge about the relationships between play and various areas of development, it appears that measures of play would enhance the information gained during evaluations of young children and contribute to the treatment validity of these assessments. Though the play-based assessment literature has expanded, the need to continue evaluating the psychometric properties of these measures remains. By comparing scores on a norm-referenced play scale with corresponding scores on a standardized measure of early social emotional skills, we provide herein information on the utility of a play-based measure with a sample of preschool children considered to be at risk for academic difficulties.

\section{PEER INTERACTIONS, SOCIAL COMPETENCE, AND SCHOOL SUCCESS}

A major focus of preschoolers' development is on socialization. Children must learn skills such as cooperation, sharing, helping, and problem solving (Johnson, Christie, \& Yawkey, 1999). In addition, the ability to establish and maintain positive peer relationships is crucial to the development of social competence and comprises a critical developmental milestone for preschool children (Guralnick, 1993). Engagement in give-and-take activities provides important opportunities for the development of social competence and emotional regulation (Kemple, 1991; Ladd \& Coleman, 1993). The establishment of effective and appropriate peer relationships has implications for children's cognitive, communicative, and social development.

Early childhood education programs typically include among their goals the establishment of satisfactory relations with peers that relate to the development of independence. Research in play and child development suggests that the quality and creative features of play can be enhanced by the involvement of peers (Rubin, Fein, \& Vandenberg, 1983). With increasing numbers of parents in the workforce, more and more children are entering day care or preschool settings at an early age, providing the opportunity for early access to peers (Ladd \& Coleman, 1993). Given this trend, it has become increasingly important for educators to develop an understanding of the nature and value of children's early peer interactions and the role these relationships play in the development of social, emotional, and cognitive development. 
The development of social competence is a critical task for young children to accomplish to function successfully in school, since socially competent children are able to recognize and respond to the established social norms operating in the school context (Kemple, 1991; Ladd \& Coleman, 1993). Previous research suggests relationships between children's social competence, popularity, and school adjustment, with socially competent children being well liked by their peers and developing positive perceptions of school (Ladd, 1990). Positive peer relations have also demonstrated a relationship with academic gains. With this information in mind, the important links between early play interactions with peers, social competence, and school success begin to emerge.

\section{PRESCHOOL ASSESSMENT}

Experts in child development know that evaluating preschoolers constitutes a fundamentally different task than assessing their school-age counterparts. Those involved in the assessment of preschoolers' cognitive abilities face particular challenges, as the behavior of these children within the testing situation can affect the accuracy of results (Nagle, 2000). Because preschoolers' cognitive abilities depend to such an extent on other skills, however, it is pertinent to examine the various domains of functioning, including social competence, emotional expression, selfregulation, coping with new situations, and play, rather than focusing solely on cognitive development (Bagnato \& Neisworth, 1991). To be consistent with the recommendations set forth in Public Law 99-457, assessment tools should have treatment validity, documented reliability and validity, and involve the active participation of parents. In addition, assessments should be multifaceted, with information from multiple sources, instruments, and settings and should take an ecological perspective that examines the child's developmental skills within social, school, and family contexts. Assessment should be convergent, involving formal and informal measurement tools to accomplish multiple purposes. Convergent assessment enhances social and treatment validity by providing the most valid estimate of developmental functioning. As we will demonstrate, the assessment of children's play behaviors is consistent with these recommendations for preschool assessment.

Play-based assessment provides information not only on developmental skills but also reflects the importance of the parent-child relationship and the significance of play as a primary context for young children's learning and development (Paget, 1999). The evaluation of play reveals children's patterns of interactions with caregivers and peers, both of which are important to consider when assessing preschoolers. Lowenthal (1997) described play-based assessments as functional, since the results they produce can be immediately linked to intervention strategies.

Assessments of play that rely on third-party ratings are appropriate because they do not rely on the child's cooperation, which is often difficult for preschoolers (Fewell \& Rich, 1987).

One such assessment tool is the Penn Interactive Peer Play Scale (PIPPS; Fantuzzo, Mendez, \& Tighe, 1998; Fantuzzo et al., 1995). The PIPPS is a rating scale designed to differentiate those children who demonstrate positive peer interactions from those who display less positive relationships, based on skills observed within play. The teacher version of the PIPPS was initially established with a sample of 312 low-income, African American children attending an urban Headstart program (Fantuzzo et al., 1995) with a refined, 32-item version later validated with a new sample of 523 children (Fantuzzo, Coolahan, Mendez, McDermott, \& Sutton-Smith, 1998). A 32-item parent version of the PIPPS identical to the teacher version was developed with a sample of 297 children to provide a congruent assessment tool to use across settings and raters (Fantuzzo et al., 1998). 
Teachers and parents of children in urban Headstart programs completed PIPPS ratings, with teacher ratings occurring after a 2-month period of familiarizing themselves with the children. Exploratory factor analyses revealed identical three-factor structures for both versions, evidencing the construct validity of the measure. Play Interaction, the first factor, serves as an indicator of children's prosocial behaviors and play strengths. The second and third factors, Play Disruption and Play Disconnection, describe more negative aspects of play. Play Disruption includes items that represent aggression and nonsocial play, while Play Disconnection represents withdrawn behaviors and lack of participation in play activities. To examine the relationship between the parent and teacher versions of the PIPPS, the two scales were correlated. Significant correlations were found between each corresponding factor for the different versions. Based on preliminary evidence, the PIPPS has demonstrated validity with inner city minority preschoolers, establishing it as a promising tool in the assessment of preschoolers' peer interactive play behaviors.

Our primary purpose in the present study was to examine relationships between young children's early play behaviors with their peers and their social competence. Within the context of that purpose, the validity of the PIPPS was further examined by comparing it to a different measure of social emotional development and extending the results to a different population than that under which it was normed.

\section{METHOD}

\section{Participants}

This study was completed in a public school district in the Southeastern United States that serves over 15,000 students in 17 schools. Data were collected from students enrolled in an early intervention program for four-year-old children considered to be at risk for future problems in school. Risk status was determined by scores on the Developmental Indicators for the Assessment of Learning-Third Edition (DIAL-3; Mardell-Czudnowski \& Goldenberg, 1998). Children were ranked in ascending order according to their percentile rankings using the 1990 census projection as the norm sample. Those whose percentile scores were between 0 and 31 were identified for placement in the program and were assigned according to the available slots.

Parents of all children in the program were contacted for participation in the study, with the exception of those children with diagnosed disabilities, including sensory impairments, and children for whom English was not their primary language. Of the 300 children in the program, permission was granted from 85 parents, resulting in 43 male and 42 female participants ranging in age from 50 to 66 months $(M=57.74, S D=3.86)$. Eighty children were Caucasian, 4 were African American, and 1 was Hispanic. Because this particular study reflects only a portion of the analyses performed on this data set, the results reported reflect a smaller number of participants than the overall total of 85 .

\section{Instruments}

Penn Interactive Peer Play Scale. Parent and teacher ratings of children's play with their peers were assessed with the respective versions of the Penn Interactive Peer Play Scale (PIPPS, Fantuzzo et al., 1998). As described in the introduction, the PIPPS is a 32-item rating scale designed 
to differentiate children who display positive versus negative behaviors during play with peers. Examples of behaviors assessed by the PIPPS include helpfulness, fighting or arguing, showing positive or negative emotions, settling conflicts, and disrupting play (Fantuzzo et al., 1998). Exploratory factor analyses revealed a three-factor structure, evidencing the construct validity of the measure. The three factors include Play Interaction, which serves as an indicator of children's prosocial behaviors and play strengths, Play Disruption, which reveals aggression and nonsocial play, and Play Disconnection, which represents withdrawn behaviors and lack of participation in play activities. Based upon normative data, raw scores can be converted to $T$ scores, although for the current analyses, raw scores were utilized. The ranges of raw scores presented in the $T$-score conversion programs for the PIPPS and the ranges for the present sample are presented in Table 1.

Table 1

Raw Score Ranges for PIPPS

\begin{tabular}{lcc}
\hline & Minimum & Maximum \\
\hline From Fantuzzo et al. (1995) & & \\
Parent PIPPS & 14 & 40 \\
$\quad$ Play Interaction & 10 & 40 \\
$\quad$ Play Disruption & 9 & 36 \\
$\quad$ Play Disconnection & & \\
Teacher PIPPS & 8 & 32 \\
$\quad$ Play Interaction & 13 & 47 \\
$\quad$ Play Disruption & 9 & 32 \\
$\quad$ Play Disconnection & & \\
Present sample & & 37 \\
Parent PIPPS & 22 & 32 \\
$\quad$ Play Interaction & 12 & 22 \\
$\quad$ Play Disruption & 9 & 36 \\
$\quad$ Play Disconnection & & 34 \\
Teacher PIPPS & 17 & 27 \\
$\quad$ Play Interaction & 10 & \\
$\quad$ Play Disruption & 9 & \\
Play Disconnection & & \\
\hline
\end{tabular}

Concurrent validity of the PIPPS was established by comparing the factor patterns to factors on the Social Skills Rating System (SSRS; Gresham \& Elliot, 1990). Results revealed positive correlations between the Play Interaction factor on the PIPPS and the social skills factors on the SSRS, as well as between the Play Disruption and Disconnection factors and the SSRS behavior problems factors. Negative correlations were found between the PIPPS Play Interaction factor and the SSRS problem behaviors factors and between the Play Disruption and Play Disconnection factors and the social skills factors. These results were comparable for both the parent and teacher versions of the PIPPS.

Vineland Social-Emotional Early Childhood Scales. The Vineland Social-Emotional Early Childhood Scales (SEEC; Sparrow, Balla, \& Cicchetti, 1998), an early childhood measure of social-emotional development, were administered to parents and teachers of children in the study. 
Based on the well-accepted Vineland Adaptive Behavior Scales (ABS), the SEEC uses a semi-structured interview format with an informant who is familiar with the child's behavior. The SEEC Scales, which include Interpersonal Relationships, Play and Leisure Time, and Coping Skills, were derived from the Socialization Domain of the Vineland and are appropriate for use with children from birth through 5 years, 11 months. A Social-Emotional Composite score is obtained from the three scales, which provides information about children's attention skills, social interactions, construction and observation of relationships, self-regulation and understanding of the expression of emotions. Standard scores with a mean of 100 and standard deviation of 15 are obtained for each of the scales and the composite.

The psychometric properties of the SEEC, described in the test manual, provide support for the reliability and validity of the scales. Internal consistency was determined using a Rasch-based split-half procedure. Median coefficient values for the scales ranged from .80 to .87 , indicating satisfactory internal consistency. The median coefficient for the composite was .93, which is high. For the four-year-old portion of the sample $(N=200)$, internal consistency coefficients were as follows: Interpersonal Relationships .84, Play and Leisure Time .85, Coping Skills .89, and Composite .96. Corresponding standard errors of measurement for the same age group ( $N=200)$ were $6.0,5.8,5.0$, and 3.0 , respectively.

Test-retest reliability was also reported as high in a subsample of 112 children ages 3 years, 0 months through 5 years, 11 months with 2- to 4-week intervals between administrations. Reliability coefficients for this age range were as follows: Interpersonal Relationships=.77, Play and Leisure Time $=.76$, Coping Skills $=.74$, and Composite $=.79$. Mean differences between standard scores on the first and second administrations for the same age range were 2.9, 0.2, 3.1, and 2.4 , respectively. Test-retest coefficients with different interviewers were slightly lower. The SEEC scales were administered to parents of 78 children aged 6 months through 5 years, 11 months, with intervals ranging from 1 to 14 days $(M=8)$ between administrations. Coefficients for the three scales and composite were $.47, .47, .60$, and .50 , respectively. Intraclass correlation procedures were used with the same subsamples of children assessed in the test-retest reliability estimates. These correlations were compared to the Pearson correlations, with no resulting differences, indicating sufficient interrater reliability.

The content validity of the SEEC scales was supported by the careful procedures used in their development. In developing the items, an in-depth literature review on child development was conducted, as well as an investigation of current adaptive behavior scales and extensive survey of research and clinical experience. The item pool was reviewed by experts and determined to be appropriately representative of those skills necessary for the development of social sufficiency. In addition, steady increases in mean raw scores for children across the age ranges and in all scales were observed, thus supporting the developmental progression of scores.

Convergent validity was assessed in two studies comparing the Socialization Domain of the Vineland ABS, Survey Form with the Battelle Developmental Inventory Personal-Social Domain (BDI; Newborg, Stock, Wnek, Guidubaldi, \& Svinicki, 1984; Johnson, Cook, \& Kullman, 1992) and the Scales of Independent Behavior Early Developmental Scale (SIB; Bruininks, Woodcock, Weatherman, \& Hill, 1984). The resulting coefficients, .65 ( $N=67)$ and .63 ( $N=66)$, respectively, support the convergent validity of the measure. Discriminant validity was established by the low coefficients resulting when the ABS was compared to the Kaufman Assessment Battery for Children (K-ABC; Kaufman \& Kaufman, 1983) Mental Processing Composite ( $r=.13)$ and Achievement 
Scale $(r=.12)$ and the Peabody Picture Vocabulary Test-Revised (PPVT-R; Dunn \& Dunn, 1981) $(r=.19)$.

\section{Procedure}

Eight of the nine elementary schools in the school district participated in the study. Once informed consent was obtained, parents and teachers were contacted to schedule SEEC interviews and to complete the PIPPS. The teacher measures were administered at least 6 to 8 weeks after the children started the school year, to allow time for the teachers to become familiar with the students. Data collection began in November and continued through February of the same school year. The majority of the parent data was collected at the child's school, although many of the Vineland interviews were conducted by phone. All interviews were conducted by graduate students in school psychology with advanced training in interviewing and assessment. Attempts were made to have data collected from parents and teachers of the same students within a time period of 2 to 3 weeks. In most cases this was accomplished, with the greatest time frame between ratings of the same student being approximately 1 month.

Although attempts were made to obtain information for all portions of the data from each subject, in some cases it was not possible to obtain data on one or more of the measures. PIPPS scores were obtained from 83 parents and 85 teachers, while SEEC scores were collected from 80 parents and 73 teachers. With regard to the lower number of Teacher SEEC scores, the time-consuming nature of the SEEC interviews precluded teachers from completing this aspect of the data for all participating children in their classrooms.

\section{RESULTS}

Table 2 presents the mean scores and standard deviations on the PIPPS and SEEC. Although gender differences were not a focus of the study, because there were almost equal numbers of males and females, comparisons of scores based on gender were performed. Analysis of variance revealed significant differences between mean Parent PIPPS scores for males and females on the Play Interaction and Play Disconnection scales $(F(1,81)=12.56, p=.001 ; F(1,81)=11.84, p=$ .001). In contrast, no significant differences emerged between males and females for parent scores on the Play Disruption scale $(F(1,81)=1.01, p=.30)$. For the Teacher PIPPS, no significant differences were found between any of the scales with regard to gender. Table 3 presents a comparison of mean scores and standard deviations on the PIPPS for males and females.

Prior to analyzing the data statistically, the distribution of scores was examined to consider issues that might pose threats to the assumptions of canonical correlation and multiple regression. Correlations between the PIPPS scores and Collinearity Statistics were found to be at appropriate levels, thus ruling out the potential for multicollinearity. An investigation of the Normal Probability Plots and the residuals scatterplots revealed no violations of the assumptions of Normality, Linearity, or Homoscedasticity.

Three separate statistical techniques were used to analyze the relationships between peer interactive play and social emotional skills. First, to examine the degree of relatedness between variables, simple correlations were computed between scores on the Parent and Teacher PIPPS 
and SEEC. Table 4 illustrates the correlations that emerged between the Parent PIPPS and SEEC scores and between Teacher PIPPS and SEEC scores. No significant correlations were found between the Parent PIPPS and Teacher SEEC scales or between the Teacher PIPPS and Parent SEEC scales.

Table 2

Means and Standard Deviations on Measures

\begin{tabular}{lrr}
\hline Measure & $M$ & $S D$ \\
\hline PIPPS raw scores & & \\
Parent PIPPS & & \\
$\quad$ Play Interaction & 29.40 & 3.58 \\
Play Disconnection & 13.78 & 2.94 \\
$\quad$ Play Disruption & 20.77 & 4.00 \\
Teacher PIPPS & & \\
$\quad$ Play Interaction & 27.13 & 3.96 \\
Play Disconnection & 15.86 & 3.75 \\
$\quad$ Play Disruption & 17.66 & 6.03 \\
SEEC standard scores & & \\
Parent SEEC & & 13.60 \\
Interpersonal Relationships & 99.69 & 12.29 \\
Play and Leisure Time & 94.88 & 10.72 \\
Coping Skills & 101.50 & 12.15 \\
Composite & 97.73 & \\
Teacher SEEC & & 17.29 \\
Interpersonal Relationships & 95.90 & 10.05 \\
Play and Leisure Time & 94.26 & 11.72 \\
Coping Skills & 106.44 & 13.23 \\
Composite & 98.01 & \\
\hline
\end{tabular}

To further examine the multivariate relationships between the PIPPS and SEEC, a series of canonical correlations were performed. Canonical correlation is a multivariate technique used to examine the complex interactions between two sets of variables (Weiss, 1972) and was considered appropriate to use with the present data set because of the multifaceted nature of the variables involved. Canonical correlation analyses were computed for parent and teacher ratings on the PIPPS and the SEEC, with all three scales on each measure included in the analyses. The PIPPS domains included Play Interaction, Play Disruption, and Play Disconnection and the SEEC subscales included Interpersonal Relationships, Play and Leisure Time, and Coping Skills.

One significant canonical correlation resulted from the parent comparisons (canonical $R=$ $.54, p=.0001$ ) that accounted for $29 \%$ of the variance. Conceptually, this variable was labeled Prosocial Involved because it was characterized by strong positive relations among Interpersonal Relationships, Play Interaction, Play and Leisure Time, and Coping Skills. Play Disruption loaded negatively on this variate pair [Wilks's lambda $=.69, F(9,180)=3.31, p=.0009$ ]. The pattern of 
loadings associated with this variate is reported in Table 5. Analysis of canonical redundancy indicated that $14 \%$ of the variance in the parent PIPPS ratings could be explained by the SEEC. Alternatively, the PIPPS factors accounted for $20 \%$ of the variance in the SEEC.

The final step in these analyses, which was used to obtain a better understanding of the impact of each of the individual PIPPS scales on the SEEC factors, was to employ multiple regression analyses. Multiple regression was performed with all three PIPPS factors entered into the equation as the independent variables. For the first analysis, parent ratings on the SEEC Interpersonal Relationships scale were entered as the dependent variable. The overall model was significant [Adjusted $R 2=.22, F(3,76)=8.51, p=.0001$ ] and accounted for $22 \%$ of the variance in Interpersonal Relationships. An examination of the standardized beta weights indicated that Play Interaction contributed most to the equation, followed by Play Disruption. Play Disconnection did not contribute significantly to the model (See Table 6).

Table 3

Means and Standard Deviations on PIPPS by Gender

\begin{tabular}{|c|c|c|}
\hline Measure & $M$ & $S D$ \\
\hline \multicolumn{3}{|l|}{ Parent PIPPS } \\
\hline \multicolumn{3}{|c|}{ Play Interaction } \\
\hline Males & 28.14 & 3.60 \\
\hline Females & 30.75 & 3.07 \\
\hline \multicolumn{3}{|c|}{ Play Disconnection } \\
\hline Males & 14.79 & 2.92 \\
\hline Females & 12.70 & 2.58 \\
\hline \multicolumn{3}{|c|}{ Play Disruption } \\
\hline Males & 21.21 & 3.88 \\
\hline Females & 20.30 & 4.12 \\
\hline \multicolumn{3}{|l|}{ Teacher PIPPS } \\
\hline \multicolumn{3}{|c|}{ Play Interaction } \\
\hline Males & 26.56 & 4.23 \\
\hline Females & 27.71 & 3.62 \\
\hline \multicolumn{3}{|c|}{ Play Disconnection } \\
\hline Males & 15.51 & 4.00 \\
\hline Females & 16.21 & 3.54 \\
\hline \multicolumn{3}{|c|}{ Play Disruption } \\
\hline Males & 18.37 & 6.67 \\
\hline Females & 16.93 & 5.28 \\
\hline
\end{tabular}

Notes. Parent PIPPS: Males $N=43$, Females $N=40$. Teacher PIPPS: Males $N=43$, Females $N=42$.

In the second multiple regression analysis, Play and Leisure Time served as the dependent variable. Although the overall model was significant [Adjusted $R 2=.18, F(3,76)=6.57, p=$ $.001]$, only Play Interaction contributed significantly to the model. The overall model accounted for $17.5 \%$ of the variance in Play and Leisure Time. The final analysis involved Coping Skills as the dependent variable. A significant model emerged [Adjusted $R 2=.11, F(3,76)=4.27, p=$ 
.008] which accounted for $11.1 \%$ of the variance. Play Disruption and Play Interaction contributed almost equally to the equation, while Play Disconnection did not make a significant contribution. Table 6 outlines the standardized beta coefficients for these analyses.

As with the Parent comparisons, canonical correlation analysis was used to examine the relationships between Teacher ratings on the PIPPS and SEEC. Two significant canonical correlations emerged [Wilks's lambda $=.46, F(9,163)=6.84, p=.0001$ ]. The first correlation (canonical $R=.68, p=.0001$ ) accounted for $46 \%$ of the variance, while the second (canonical $R=.38$, $p=.05$ ) accounted for $15 \%$. The pattern of loadings associated with these correlations is given in Table 7. The first variate pair, called Conscientious-Involved, was defined by strong positive associations among Coping Skills, Play Interaction, Interpersonal Relationships and Play and Leisure Time. Play Disruption and Play Disconnection loaded negatively on this variate pair. The second variate pair, called Engaged, was characterized by strong positive relationships between Interpersonal Relationships and Play Disruption. Redundancy analysis indicated that the SEEC factors accounted for $33 \%$ of the variance in the PIPPS, while the PIPPS factors accounted for $31 \%$ of the variance in the SEEC.

Table 4

Correlations Between PIPPS and SEEC

\begin{tabular}{|c|c|c|c|c|c|c|}
\hline & \multicolumn{3}{|c|}{ Parent PIPPS } & \multicolumn{3}{|c|}{ Teacher PIPPS } \\
\hline & $\begin{array}{c}\text { Play } \\
\text { Interaction }\end{array}$ & $\begin{array}{c}\text { Play } \\
\text { Disruption }\end{array}$ & $\begin{array}{c}\text { Play } \\
\text { Disconnection }\end{array}$ & $\begin{array}{c}\text { Play } \\
\text { Interaction }\end{array}$ & $\begin{array}{c}\text { Play } \\
\text { Disruption }\end{array}$ & $\begin{array}{c}\text { Play } \\
\text { Disconnection }\end{array}$ \\
\hline Parent SEEC $(N=80)$ & & & & $(N=80)$ & & \\
\hline Interpersonal Relationships & $.42^{* *}$ & $-.34^{* *}$ & -.16 & .10 & -.13 & -.13 \\
\hline Play \& Leisure & $41^{* *}$ & $-.25^{*}$ & -.21 & .11 & -.21 & -.07 \\
\hline Coping Skills & $.28^{*}$ & $-.29 * *$ & -.20 & .17 & -.18 & -.22 \\
\hline Composite & $.45^{* *}$ & $-.35^{* *}$ & $-.22 *$ & .14 & -.20 & -.15 \\
\hline Teacher SEEC $(N=73)$ & & & & $(N=73)$ & & \\
\hline Interpersonal Relationships & -.03 & .08 & .17 & $.51 * *$ & $-.29 *$ & $-.49 * *$ \\
\hline Play \& Leisure & -.09 & .06 & .08 & $.39 * *$ & $-.29 *$ & $-.37 * *$ \\
\hline Coping Skills & .11 & .06 & -.02 & $.52 * *$ & $-.57 * *$ & $-.47 * *$ \\
\hline Composite & -.00 & .08 & .10 & $.55^{* *}$ & $-.43^{* *}$ & $-.51^{* *}$ \\
\hline
\end{tabular}

${ }^{*}$ Correlation is significant at the 0.05 level (2-tailed). ${ }^{* *}$ Correlation is significant at the 0.01 level (2-tailed).

Multiple regression analyses were again performed with the three Teacher PIPPS factors entered into the equation as the independent variables. When teacher ratings on the SEEC Interpersonal Relationships scale were entered as the dependent variable, the resulting model was significant (Adjusted $R 2=.31, F(3,69)=11.52, p=.0001$ ) and accounted for $30.5 \%$ of the variance in the Interpersonal Relationships score. Play Interaction contributed the most to the equation, followed by Play Disconnection. Play Disruption did not contribute significantly to the model. The standardized beta weights are presented in Table 8. 
Table 5

Canonical Structure of Parent PIPPS and SEEC

\begin{tabular}{lc}
\hline Variable & Canonical variate set \\
\hline SEEC Subscale & Prosocial Involved \\
Interpersonal Relationships & .93 \\
Play and Leisure Time & .83 \\
Coping Skills & .70 \\
PIPPS dimension & \\
Play Interaction & .84 \\
Play Disruption & -.68 \\
Play Disconnection & -.40 \\
\hline
\end{tabular}

Notes. $N=80$. Loadings $\geq .50$ are considered appreciable and are italicized.

Table 6

Multiple Regression Between Parent PIPPS and Parent SEEC Scales

\begin{tabular}{lccc}
\hline & \multicolumn{3}{c}{ PIPPS } \\
\cline { 2 - 4 } & Play Interaction & Play Disruption & Play Disconnection \\
\hline SEEC & & & \\
$\quad$ Interpersonal Relationships (Adjusted $R^{2}=.22$ ) & & & .02 \\
$\quad B$ & .38 & -.28 & .86 \\
$p$ & .001 & .01 & -.07 \\
Play and Leisure Time (Adjusted $R^{2}=.18$ ) & & & .55 \\
$B$ & .36 & .17 & -.07 \\
$p$ & .001 & -.23 & .52 \\
Coping Skills (Adjusted $R^{2}=.11$ ) & .22 & .05 & \\
$B$ & .05 & & \\
$p$ & & & \\
\hline
\end{tabular}

The second analysis involved teacher ratings on the SEEC Play and Leisure Time Scale. The overall model was significant [Adjusted $R 2=.16, F(3,69)=5.4, p=.002$ ] and accounted for $15.5 \%$ of the variance in Play and Leisure Time. None of the independent variables contributed significantly to the model. The final multiple regression analysis between the teacher PIPPS and teacher SEEC Coping Skills scale resulted in a significant model [Adjusted $R 2=.38, F(3,69)=$ $15.89, p=.0001$ ]. This model accounted for $38.3 \%$ of the variance in Coping Skills. Play Disruption contributed the most to the equation, followed by Play Disconnection. Play Interaction did not contribute significantly to the model. The standardized beta coefficients for these models are presented in Table 8. 


\section{DISCUSSION}

The significant relationships found between teacher and parent ratings of children's play with their peers and their corresponding observations of social-emotional development support the important role of play and peer relations in the development of social competence. The skills needed to establish and maintain positive relationships with peers represent critical developmental milestones for preschoolers, requiring them to contend with a variety of social tasks, including gaining entry into peer groups, resolving conflicts, and maintaining play (Guralnick, 1993; Rubin, et al., 1983). Peer interactions also provide opportunities for children to learn to regulate their emotions and to develop a sense of shared understanding of social norms and expectations. Children who interact positively with peers tend to be more popular and have continuing access to situations in which their social competence is reinforced by peers (Hatch, 1987). On the other hand, children who lack peer competence tend to be unpopular and are denied access to experiences that provide opportunities to develop and practice social skills. Engagement in give-andtake activities provides important opportunities for the development of social competence and emotional regulation (Kemple, 1991; Ladd \& Coleman, 1993). In addition, the development of social competence is a critical task for young children to accomplish to function successfully in school by permitting children to recognize and respond to the established social norms in the school context.

Table 7 Canonical Structure of Teacher PIPPS and SEEC

\begin{tabular}{lcr}
\hline & \multicolumn{2}{c}{ Canonical variate set } \\
\cline { 2 - 3 } Variable & Conscientious-Involved & Engaged \\
\hline SEEC Subscale & .77 & .64 \\
Interpersonal Relationships & .62 & .26 \\
Play and Leisure Time & .93 & -.23 \\
Coping Skills & & .23 \\
PIPPS dimension & .86 & .57 \\
Play Interaction & -.82 & -.33 \\
Play Disruption & -.79 & \\
Play Disconnection & &
\end{tabular}

Notes. $N=73$. Loadings $\geq .50$ are considered appreciable and are italicized.

More specifically, the significant relationships between scores on the Parent PIPPS and SEEC suggest that children who are competent players also display strong social-emotional skills (Hatch, 1987; Hazen \& Black, 1989; Kemple, 1991) while children who are negative and aggressive during play interactions tend to display lower levels of social-emotional development (Coie \& Kupersmidt, 1983; Dodge, 1983; Hatch, 1987). Similar findings were reported by Fantuzzo and colleagues (1998), who found that preschoolers rated as exhibiting high levels of Play Interaction on the parent version of the PIPPS were also rated high on the Social Skills Rating System (SSRS; Gresham \& Elliott, 1990). Positive correlations emerged between the Play Interaction and the Self Control, Interpersonal Skills, and Verbal Assertion scales on the SSRS. The negative association with Play Disruption is also consistent with previous results. Play Disruption includes items that 
represent aggressive and antisocial play behaviors (Fantuzzo et al., 1998), and these are in contrast to the prosocial skills demonstrated by the other scales. Negative correlations were found between ratings of Play Disruption and Play Disconnection and the social skills factors in Fantuzzo and colleagues' study. The current findings provide further support for the validity of the PIPPS, in that a relationship was established between the PIPPS and another standardized measure of socialemotional development among a group of children with a different demographic profile.

Table 8

Multiple Regression Between Teacher PIPPS and Teacher SEEC Scales

\begin{tabular}{lccc}
\hline & \multicolumn{3}{c}{ PIPPS } \\
\cline { 2 - 4 } & Play Interaction & Play Disruption & Play Disconnection \\
\hline SEEC & & & \\
$\quad$ Interpersonal Relationships (Adjusted $R^{2}=.31$ ) & & .08 & -.33 \\
$\quad B$ & .39 & .52 & .006 \\
$p$ & .005 & & -.22 \\
Play and Leisure Time (Adjusted $R^{2}=.16$ ) & & .05 & .09 \\
$B$ & .25 & .71 & -.23 \\
$p$ & .10 & -.36 & .04 \\
Coping Skills (Adjusted $R^{2}=.38$ ) & .19 & .003 & \\
$B$ & .14 & & \\
$p$ & & & \\
\hline
\end{tabular}

The use of canonical correlations helped to clarify the relationships between these multidimensional parent measures. The canonical variate that emerged from this analysis, Prosocial Involved, reflected strong, positive relationships between Interpersonal Relationships, Play Interaction, Play and Leisure Time, and Coping Skills, and a negative association with Play Disruption.

This variate, which accounted for almost one third of the variance, indicates that children who scored high on Play Interaction, based on parent ratings, were also rated positively in terms of their social-emotional skills. These children also scored low on parent ratings of Play Disruption. These findings are relatively straightforward, since Play Interaction reflects children's play strengths, including prosocial skills such as helping and comforting others and encouraging others to participate in play (Fantuzzo et al., 1998). Children who display these traits also tend to have positive interpersonal relationships, strong coping skills, and engage in play and leisure activities at developmentally appropriate levels.

Previous research provides support for this finding. Putallaz and Gottman (1981) examined the strategies used by 40 popular and unpopular children in second and third grades to gain entry into play groups. Differences were observed between the strategies used, with unpopular children being more likely to disagree, to express their opinions and feelings more strongly, and to talk about themselves inappropriately in attempt to divert the group's attention to themselves rather than integrating themselves into the ongoing group interactions. Similar results by Hazen and Black (1989) indicated popular children tend to use clear and direct communication, including eye contact and gestures, to make relevant responses to children's comments, and to provide reasons 
when they rejected peers, thus promoting the continuation of interactions. Thus, a relationship between peer interactions and social competence has been previously established and is supported by these findings.

The Interpersonal Relationships scale demonstrated the strongest loadings in this variate pair. This scale involves items that represent responsiveness to others, recognizing and expressing emotions, responding to and initiating social communication, and participating in cooperative interactions (Sparrow et al., 1998). These characteristics are similar to those captured by the PIPPS Play Interaction scale and represent prosocial skills, which appear to drive this relationship. Previous research supports a relationship between children's popularity with peers and their ability to understand emotional expressions and situations. In one such study, preschool children who were able to identify emotional expressions during an activity also tended to be well-liked by peers, as indicated by sociometric techniques, observations, and teacher ratings (Denhan, McKinley, Couchoud, \& Holt, 1990). These researchers concluded that popular children are better at discerning the emotional reactions of peers during interactions and thus, better able to respond to them while less popular children may tend to misinterpret emotional states and react inappropriately. These results parallel the current findings in which children who were responsive to the emotional states of others were also positive in their peer play interactions.

Ladd, Price, and Hart (1988) discovered similar relationships between peer behavior and peer status in preschoolers. Observations and sociometric ratings provided evidence that children who were argumentative and aggressive at the beginning of the school year were more likely to be rejected by the end of the school year. Additional research found a relationship between peer relations and school adjustment. Ladd (1990) found that among kindergartners, children with more friends in the classroom at the time of school entry developed more positive perceptions of school by the second month, and those children who maintained these friendships throughout the school year tended to have even more positive attitudes toward school as the year progressed. Additionally, children who made new friends in the classroom displayed gains in school performance, while children rejected by peers early in the school year developed negative attitudes toward school, tended to avoid school, and displayed lower levels of school performance during their kindergarten year. This evidence that children who are unpopular may be at risk for problems with school adjustment is important to keep in mind when analyzing the current findings, as children who scored high on Play Disruption are likely to experience similar risks.

The fact that Play Disconnection did not contribute to this relationship may be a reflection of the nature of this factor. Play Disconnection contains items that describe withdrawn behavior and nonparticipation in peer play. Children who are disconnected are not involved in play and therefore are not a part of the Prosocial-Involved group. This relationship reflects children who not only display prosocial skills, but also those who are actively involved in play interactions with peers. As Putallaz and Gottman (1981) found, children who are unpopular tend to be ignored and rejected rather than being accepted into peer groups. Children who score high on Play Disconnection probably are not very popular and will therefore miss out on opportunities to engage in peer play activities. As mentioned by Guralnick (1993), gaining entry into peer groups is a social task that must be accomplished to establish and maintain peer relationships. Since those children who are disconnected tend to be withdrawn and do not enter into play situations, they miss out on this important early developmental task. 
Significant correlations were also found between the teacher PIPPS and SEEC scales. Positive correlations emerged between the Play Interaction scale and each of the SEEC scales and the Composite, and negative correlations resulted between the Play Disruption and Play Disconnection scales and each of the SEEC scales and the Composite. As was the case with the parent ratings, these findings were consistent with the findings from Fantuzzo et al.'s $(1995 ; 1998)$ validation studies of the teacher PIPPS. Results from that study revealed positive correlations between the Play Interaction factor and the social skills factors on the Social Skills Rating System (SSRS; Gresham \& Elliott, 1990), including Self Control, Interpersonal Skills, and Verbal Assertion. Negative correlations were also found between the Play Disruption and Play Disconnection factors and the social skills factors. Thus, in addition to establishing a relationship between peer play and social-emotional development, the current findings provide further support for the validity of the Teacher PIPPS.

Canonical correlation analysis resulted in two canonical variate pairs, which together accounted for over half of the variance. The first variate pair, which alone accounted for almost half of the variance, was called Conscientious-Involved. This variate pair is similar to the Prosocial-Involved pair that resulted from the analysis of the parent ratings, in that it is defined by strong positive associations between Coping Skills, Play Interaction, Interpersonal Relationships, and Play and Leisure Time and a negative association with Play Disruption. However, this variate is also negatively associated with Play Disconnection. As with Prosocial-Involved, children who were rated by their teachers as strong, positive players were also reported to display positive socialemotional skills. However, in contrast to the Prosocial-Involved variate, in which the Interpersonal Relationships scale loaded most strongly, the Conscientious-Involved variate pair is largely driven by the Coping Skills scale. This scale contains items which represent responsible behaviors such as obeying rules, controlling impulses, sharing, being dependable, sensitive, polite, and trustworthy, and displaying good manners (Sparrow et al., 1998). Whereas the Prosocial-Involved variate represents children who interact positively with others and have an understanding of emotions, the Conscientious-Involved variate reflects an understanding of social norms and expectations that guides behavior.

Support for a relationship between responsible behaviors and peer interactions is found in Vygotsky's (1978) theory, which asserts that as children follow rules within the context of play, they are developing an understanding of social norms and expectations and learning to act against their immediate impulses. Establishing and sustaining positive peer interactions and maintaining play are important social tasks which children must contend with to make and keep friends and be successful at school (Guralnick, 1993; Hatch, 1987; Kupersmidt, Coie, \& Dodge, 1990). Children who scored high on the Coping Skills scale demonstrated the ability to respond appropriately to the rules and expectations of play situations and were successful in their interactions with peers.

That this variate pair is negatively related to Play Disconnection suggests that children who are withdrawn and tend to stay outside of the play group do not display positive coping skills or compliant behaviors. For teachers, observations of children's peer interactions often provide the best information available about their social competence (Kemple, 1991). Perhaps these students' lack of participation precluded their teachers from observing these positive behaviors.

The current findings are important to consider in light of research conducted by Ladd (1990), who explored the role that peer relations play in children's school adjustment and found that children's lack of popularity with peers puts them at risk for problems with school adjustment. 
These important findings are consistent with current results in which children who scored high on Play Disconnection did not develop positive coping skills or learn to respond appropriately to social norms and expectations. Because these children tend to be withdrawn and avoid peer interactions, they likely do not have many friends and may therefore be at similar risk for school adjustment difficulties.

The second canonical variate, labeled Engaged, was characterized by positive loadings between Interpersonal Relationships and Play Disruption. Although this variate pair did not account for as much of the variance as the Conscientious-Involved pair, it still contributes significantly to the relationship between the PIPPS and SEEC. Although intuitively, these scales appear to reflect substantially different behaviors, a closer examination clarifies the relationship. The Interpersonal Relationships scale includes items that represent positive social interactions, while Play Disruption characterizes aggressive, antisocial play behaviors. However, children rated as high on both scales share one similar characteristic: they are actively engaged in play interactions. The children may be interacting positively or negatively with peers during play, but regardless of the quality of the interactions, they are engaged with peers. Play Disconnection did not load on this variate pair, as children rated high on this scale are withdrawn and do not participate in play.

The research reviewed in this section reflects the important positive relationships between peer interactions, popularity, social-emotional development, and school adjustment (Denham \& Holt, 1993; Hazen \& Black, 1989; Ladd, 1990; Ladd, et al., 1988; Ladd \& Price, 1987). Based on that research, children who display high levels of Play Disruption can be expected to be unpopular and experience difficulties adjusting to school. The Engaged variate pair represents children who scored high on Interpersonal Relationships, which is an indicator of responsiveness, recognizing and expressing emotions, initiating and responding to social communication, and participating in cooperative interactions (Sparrow et al., 1998). The Engaged variate also reflects high scores on Play Disruption, which is an indicator of aggressive, antisocial behaviors. One positive implication of this relationship is that although these children may be interacting negatively during peer interactions, they are involved with peers and are therefore exposed to opportunities for growth through engagement in give-and-take activities (Kemple, 1991). The concern is that through their negative interactions, these children will be rejected and will eventually become unpopular, losing access to peer groups (Pullatz \& Gottman, 1981).

These findings have important implications for those individuals involved in the assessment of young children. As a profession, school psychology has not made the evaluation of play behaviors an integral part of the assessment process. Given the extant literature demonstrating the important relationships between play and child development, it appears that the assessment of play behaviors should become standard practice. This is particularly true for preschool children, for whom the traditional intelligence and achievement test battery does not represent best practice. The current findings support the use of parent and teacher ratings of play behaviors with young children. The use of such measures is one step toward making preschool assessment more ecologically valid by allowing for the collection of information about children's natural behaviors in different contexts.

In addition, the significant correlations between parent and teacher ratings on the PIPPS and SEEC reflect important relationships not only between these two particular measures, but also between two important constructs: peer interactive play and social-emotional development. Given the importance of social emotional development to children's success in school, knowledge of 
children's play behaviors in this context should prove especially valuable. For children who display poor play behaviors or who fail to engage in play with peers, specific play-based interventions should be developed to improve these behaviors. It may be assumed from these findings that helping children learn to interact more positively with peers during play will positively affect their success in school. This finding is exciting in that it provides yet another avenue for educators who provide early intervention services to young children to pursue.

Another important finding involves the utility of the PIPPS. Given the significant relationships between ratings of peer interactive play and school success, it may be possible for psychologists to use the PIPPS in the assessment of social-emotional functioning. The PIPPS is a relatively brief self-report measure that provides information about children's play behaviors from two important sources and may serve as a valid addition to an assessment battery.

One aspect of the current findings that should be addressed briefly includes the lack of significant correlations between parent and teacher ratings on the PIPPS and SEEC. A lack of convergence between parent and teacher ratings is supported in the literature (Kaufman, Swan, \& Wood, 1980; Kazdin, 1979; Morris \& Arrant, 1978; Simpson \& Halpin, 1986), with comparisons of the ratings of behavioral and emotional problems generally producing low correlations. Although a discussion of the issue of convergence is beyond the scope of the present article, the issue will be discussed in a subsequent paper summarizing that aspect of the current data set.

The issues of sample size and power likely represent a limitation of the current study and should be briefly mentioned. Because the size of the current sample represents a minimum for the types of analyses conducted, the results should be interpreted with some caution. Although significant correlations were found between scores on the PIPPS and SEEC, they tended to be low to moderate in magnitude.

Characteristics of the sample should also be considered when interpreting these findings. The sample used in the current study differs substantially from the normative sample used in the development of the PIPPS. The current sample consisted of primarily Caucasian children with "at-risk" status living in a relatively rural area while the PIPPS was normed on African American children in urban Headstart programs. Group comparisons of PIPPS raw scores to those in the standardization group revealed a narrower range of scores for the current sample. However, the current findings indicate that the PIPPS can be used validly with other demographic groups of preschool children.

More research is needed to examine the relationship between social and academic competence in young children. Recent findings from a longitudinal study indicated a bidirectional relationship between these two domains (Welsh, Parke, Widaman, \& O’Neil, 2001). Specifically, the authors reported that academic competence influences social competence in a positive direction during first through third grades and that between second and third grades, social competence begins to exert influence on academic competence, such that a reciprocal relationship emerges. Based on these findings, the authors suggest that to improve the social and academic skills of first and second graders, focusing on academic interventions would address both types of skills. 


\section{REFERENCES}

Bagnato, S.J., \& Neisworth, J.T. (1991). Assessment for early intervention: Best practices for professionals. New York: Guilford Press.

Bruininks, R.H., Woodcock, R.W., Weatherman, R.F., \& Hill, B.K. (1984). Scales of Independent Behavior. Chicago: Riverside.

Coie, J.D., \& Kupersmidt, J. (1983). A behavioral analysis of emerging social status in boys' groups. Child Development, 54, 1400-1416.

Denham, S.A., \& Holt, R.W. (1993). Preschoolers' likability as a cause or consequence of their social behavior. Developmental Psychology, 29, 271-275.

Denham, S.A., McKinley, M., Couchoud, E.A., \& Holt, R. (1990). Emotional and behavioral predictors of preschool peer ratings. Child Development, 61, 1145-1512.

Dodge, K.A. (1983). Behavioral antecedents of peer social status. Child Development, 54, 1386-1399. Dunn, L.M., \& Dunn, L.M. (1981). Peabody Picture Vocabulary Test. Circle Pines, MN: American Guidance Service.

Fantuzzo, J., Coolahan, K., Mendez, J., McDermott, P., \& Sutton-Smith, B. (1998). Contextually-relevant validation of peer play constructs with African American Head Start children: Penn Interactive Peer Play Scale. Early Childhood Research Quarterly, 13, 411- 431.

Fantuzzo, J., Mendez, J., \& Tighe, E. (1998). Parental assessment of peer play: Development and validation of the parent version of the Penn Interactive Peer Play Scale. Early Childhood Research Quarterly, 13, 659-676.

Fantuzzo, J., Sutton-Smith, B., Coolahan, K. C., Manz, P.H., Canning, S., \& Debnam, D. (1995). Assessment of preschool play interaction behaviors in young low-income children: Penn Interactive Peer Play Scale. Early Childhood Research Quarterly, 10, 105-120.

Fewell, R.R., \& Kaminski, R. (1988). Play skills development and instruction for young children with handicaps. In S. Odom \& M. Karnes (Eds.), Early intervention for infants and children with handicaps (pp. 145-158). Baltimore, MD: Paul Brookes.

Fewell, R.R., \& Rich, J.S. (1987). Play assessment as a procedure for examining cognitive, communication, and social skills in multihandicapped children. Journal of Psychoeducational Assessment, 2, 107-118.

Fisher, E.P. (1992). The impact of play on development: A meta-analysis. Play and Culture, 5, 159-181. Gresham, F.M., \& Elliottt, S.M. (1990). The social skills rating system. Circle Pines, MN: American Guidance Service.

Guralnick, M.J. (1993). Developmentally appropriate practice in the assessment and intervention of children's peer relations. Topics in Early Childhood Education, 13, 344-371. 
Hatch, J.A. (1987). Peer interaction and the development of social competence. Child Study Journal, 17, 169-183.

Hazen, N.L., \& Black, B. (1989). Preschool peer communication skills: The role of social status and interaction context. Child Development, 60, 867-876.

Johnson, J.E., Christie, J.F., \&Yawkey, T.D. (1999). Play and early childhood development (2nd ed.). NewYork: Longman. Johnson, L.J., Cook, M.J., \& Kullman, A.J. (1992). An examination of the concurrent validity of the Batelle Developmental Inventory as compared with the Vineland Adaptive Scales and Bayley Scales of Infant Development. Journal of Early Intervention, 16(4), 353-359.

Kaufman, A.S., \& Kaufman, N.L. (1983). Kaufman Assessment Battery for Children. Circle Pines, MN: American Guidance Service.

Kaufman, A.S., Swan,W.W., \&Wood, M.M. (1980). Do parents, teachers, and psychoeducational evaluators agree in their perceptions of the problems of black and white emotionally disturbed children? Psychology in the Schools, 17, 185-191.

Kazdin, A.E. (1979). Situational specificity: The two-edged sword of behavioral assessment. Behavioral Assessment, 1, 57-75.

Kemple, K.M. (1991). Preschool children's peer acceptance and social interaction. Young Children, 48, 47-55. Kupersmidt, J.B., Coie, J.D., \& Dodge, K.A. (1990). The role of poor peer relationships in the development of disorder. In S.R. Asher \& J.D. Coie (Eds.), Peer rejection in childhood (pp. 274-309). New York: Cambridge University Press.

Ladd, G.W. (1990). Having friends, keeping friends, making friends, and being liked by peers in the classroom: Predictors of children's early school adjustment? Child Development, 61, 1081-1100.

Ladd, G.W., \& Coleman, C.C. (1993). Young children's peer relationships: Forms, features, and functions. In B. Spodek (Ed.), Handbook of research on the education of young children, (pp. 57-76). New York: MacMillan.

Ladd, G.W., \& Price, J.M. (1987). Predicting children's social and school adjustment following the transition from preschool to kindergarten. Child Development, 58, 1168-1189.

Ladd, G.W., Price, J.M., \& Hart, C.H. (1988). Predicting preschoolers' peer status from their playground behaviors. Child Development, 59, 986-992.

Lowenthal, B. (1997). Useful early childhood assessment: Play-based, interviews, and multiple intelligences. Early Child Development and Care, 129, 43- 49.

Mardell-Czudnowski, C., \& Goldenberg, D.S. (1998). Developmental Indicators for the Assessment of Learning, Third Edition. Circle Pines, MN: American Guidance Service.

Morris, J.D., \& Arrant, D. (1978). Behavior ratings of emotionally disturbed children by teachers, parents, and school psychologists. Psychology in the Schools, 15, 450- 455. 
Nagle, R.J. (2000). Issues in preschool assessment. In B.A. Bracken (Ed.), Psychoeducational assessment of preschool children. Needham Heights, MA: Allyn \& Bacon.

Newborg, J., Stock, J.R., Wnek, L., Guidubaldi, J., \& Svinicki, J. (1984). Battelle Developmental Inventory. Chicago: Riverside.

Paget, K.D. (1999). Ten years later: Trends in the assessment of infants, toddlers, preschoolers, and their families. In C.R. Reynolds \& T.B. Gutkin (Eds.), Handbook of School Psychology (3rd ed., pp. 476- 496). New York: Wiley.

Pellegrini, A.D. (1998). Play and the assessment of young children. In O.N. Saracho and B. Spodek (Eds.), Multiple perspectives on play in early childhood education (pp. 220-239). Albany, NY: State University of New York Press.

Putallaz, M., \& Gottman, J.M. (1981). An interactional model of children's entry into peer groups. Child Development, 52, 986-994.

Rubin, K., Fein, G., \& Vandenberg, B. (1983). Play. In E.M. Hetherington (Ed.), Handbook of child psychology (Vol. 4, pp. 693-774), New York: Wiley.

Simpson, R.G., \& Halpin, G. (1986). Agreement between parents and teachers in using the Revised Behavior Problem Checklist to identify deviant behavior in children. Behavioral Disorders, 12, 54-59.

Sparrow, S.S., Balla, D.A., \& Cicchetti, D.V. (1998). Vineland Social-Emotional Early Childhood Scales (SEEC). Circle Pines, MN: American Guidance Service.

Vygotsky, L.S. (1978). The role of play in development. In M. Cole, V. John-Steiner, S. Scribner, \& E. Souberman (Eds.), Mind in society (pp. 92-104). Cambridge, MA: Harvard University Press.

Weiss, D.J. (1972). Canonical correlation analysis in counseling psychology research. Journal of Counseling Psychology, 19, 241-252.

Welsh, M., Parke, R.D.,Widaman, K., \& O'Neil, R. (2001). Linkages between children's social and academic competence: A longitudinal analysis. Journal of School Psychology, 39, 463-481. 